View Article Online / Journal Homepage / Table of Contents for this issue

DERIVATIVES OF TETRAMETHYL GLUCOSE.

XI.-Derivatives of Tetramethyl Glucose.

By James Colquhoun Irvine, D.Sc., Ph.D., and Agnes Marion Moodie, M.A., B.Sc. (Carnegie Scholar).

Is previous study of alkylated sugars attention has been chiefly directed to reactions in which derivatives of a glucosidic nature are produced, and such compounds have been found to show, in general, a close relationship with the corresponding derivatives of the parent unalkylated sugars. In the present investigation, we have extended our work on tetramethyl glucose with the view of ascertaining whether the analogy also holds for derivatives generally regarded as non-glucosidic.

Our results show that tetramethyl glucose enters into all the 
characteristic reactions of the parent sugar, and, moreover, the optical rotations of the products are on the whole comparable with those of the corresponding unalkylated compounds. Several irregularities were observed, but apparently methylation has little effect on the characteristic chemical reactions of reducing sugars, except in increasing the stability of the compounds. In the first place, we have studied reactions in which the alkylated sugar might be expected to react as an alkyloxy-aldehyde, giving products in which the $\gamma$-oxidic linking, characteristic of reducing sugars and glucosides, should be absent. In the case of dextrose, the only simple condensation compounds which are regarded as derived from a hydroxy-aldehyde are the acetals, mercaptals, hydrazones, oxime, and anilide. This view of the constitution of the last compound has, however, not escaped criticism, and many arguments support the $\gamma$-oxidic structure (Ber., 1894, 27, $1287)$.

We find that in the case of tetramethyl glucose, there seems no reasonable doubt that both the oxime and anilide do possess the $\gamma$-oxidic linking in the sugar residue, and are thus to be regarded as derived from the $\alpha$ - or $\beta$-form of the sugar and not from the aldehydic isomeride. With regard to the tetramethyl glucosephenylhydrazone, our conclusions are unfortunately not supported by analytical data, but the structure of the compound seems to differ essentially from that of the anilide or oxime, and may possibly thus belong to the aldehydic type.

Tetramethyl glucoseoxime was readily prepared by the action of hydroxylamine on a methyl-alcoholic solution of the sugar. Even after repeated fractional crystallisation, the melting point was indefinite $\left(61-68^{\circ}\right)$, suggesting that the specimen was a mixture of stereoisomeric forms. The compound differed from glucoseoxime in that no indication of mutarotation could be detected, either in alcoholic or aqueous solutions. The specific rotation in methyl alcohol was $[a]_{\mathrm{D}}^{20}+25 \cdot 9^{\circ}$, a result which is comparable with the marked diminution in rotatory power observed when glucose is converted into its oxime. The constitution of the compound admits of several possibilities. Accepting the normal oxime structure, we have :

\section{I. $\mathrm{MeO} \cdot \mathrm{CH}_{2} \cdot \mathrm{CH}(\mathrm{OMe}) \cdot \mathrm{CH}(\mathrm{OH}) \cdot \mathrm{CH}(\mathrm{OMe}) \cdot \mathrm{CH}(\mathrm{OMe}) \cdot \mathrm{CH}: \mathrm{NOH}$,}

which might exist in syn-and anti-modifications. As an alternative, the following structure is possible:

$$
\text { II. } \mathrm{MeO} \cdot \mathrm{CH}_{2} \cdot \mathrm{CH}(\mathrm{OMe}) \cdot \mathrm{CH}(\mathrm{OH}) \cdot \mathrm{CH}(\mathrm{OMe}) \cdot \mathrm{CH}(\mathrm{OMe}) \cdot \mathrm{CH}<_{\mathrm{NH}}^{\mathrm{O}}
$$

On the other hand, if the sugar reacts in the $\gamma$-oxidic form, the condensation may give rise to four isomerides: 


\section{III. $\mathrm{MeO} \cdot \mathrm{CH}_{2} \cdot \mathrm{CH}(\mathrm{OMe}) \cdot \mathrm{CH} \cdot \mathrm{CH}(\mathrm{OMe}) \cdot \mathrm{CH}(\mathrm{OMe}) \cdot \mathrm{CH} \cdot \mathrm{NH} \cdot \mathrm{OH}(\alpha$ or $\beta)$. $\mathrm{I}$}

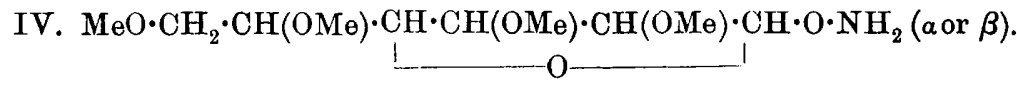

Of these possibilities, formula I alone represents a true oxime, and formula IV a true glucoside, as only in the latter case is the sugar molecule linked to the remaining group through an oxygen atom. The effect of alkylation on the compound offers a ready solution of the problem of its constitution. In the event of formulæ I or II being correct, methylation should introduce two methyl groups, and hydrolysis of the product should give aldehydic pentamethyl glucose. In the case of formula III, only one alkyloxy-group could enter the molecule, and tetramethyl glucose should be formed on hydrolysis of the product. On the other hand, formula IV represents a compound in which the methoxyl content could not be increased.

We find that by applying the silver oxide reaction to tetramethyl glucoseoxime, a derivative is formed containing five methoxyl groups, and, on hydrolysis, tetramethyl glucose is regenerated in almost quantitative amount. This result at once disposes of formulæ I, II, and IV. The absence of mutarotation may thus be explained, as, whatever the cause of this phenomenon in oximes may be, it is presumably dependent on the presence of the double bond.

Evidence was also obtained that our preparation of tetramethyl glucoseoxime consisted of two stereoisomeric forms, as, during hydrolysis, the specific rotation at first diminished very rapidly, and afterwards increased steadily to a constant value. Previous experience in the hydrolysis of alkyl glucosides has shown that this behaviour is significant of the presence of two stereoisomerides, which differ widely in their rotatory powers and rates of bydrolysis. Moreover, a similar result was observed during the hydrolysis of the pentamethylated oxime, which was doubtless also a mixture of $\alpha$-and $\beta$-forms. It might be mentioned here that the latter hydrolysis showed many features in common with that of the natural glucoside, gynocardin, described by Power and Lees (Trans., 1905, 87, 355). Contrary to expectation, the process was extremely slow, prolonged boiling with hydrogen chloride being necessary, and hydrogen cyanide was steadily evolved for some hours.

Before arriving at the above conclusion as to the constitution of tetramethyl glucoseoxime, we took the precaution of subjecting various other oximes to the joint action of silver oxide and methyl iodide. The substances selected for experiment were chosen with a view to testing the effect of the prosess on widely different types of oximes. In each case, the methylation proceeded normally, giving fully VOL. XCIII. 
alkylated derivatives. Thus ænanthaldoxime was readily couverted into a monomethyl ether, whilst salicylaldoxime and benzoinoxime gave the corresponding dimethyl ethers. This shows that the oximidogroup, in common with any other hydroxyl group which may be present, is capable of ready methylation by the silver oxide method, and the results arrived at by this process are therefore valid in deducing the constitution of oximes. The method, moreover, possesses many obvious advantages in the determination of the hydroxyl content of oximes, as the use of acetic anhydride in such estimations frequently results in molecular rupture or in nitrile formation, and, in addition, the products are often difficult to purify.

Our examination of tetramethyl glucoseanilide has led to a similar conclusion as to its constitution. The compound, which was prepared by boiling an alcoholic solution of the sugar and the base, crystallised in long needles, melting at $132-134^{\circ}$. In acetone solution, it showed a high dextrorotation $\left([\alpha]_{\mathrm{D}}^{20}+229 \cdot 5^{\circ}\right)$, and no mutarotation was observed. Apparently only one form was present in this crystalline specimen, as during hydrolysis the specific rotation decreased continuously without fluctuation. The compound was quite unaltered after several successive treatments with silver oxide and methyl iodide, and, as in no previous case has any soluble hydroxy-compound resisted the action of these reagents, we conclude that the anilide is a $\gamma$ oxidic form, and possesses the following formula :

$$
\mathrm{CH}_{3} \cdot \mathrm{O} \cdot \mathrm{CH}_{2} \cdot \mathrm{CH}\left(\mathrm{O} \cdot \mathrm{CH}_{3}\right) \cdot{ }^{\mathrm{CH}} \cdot \mathrm{CH}\left(\mathrm{O}^{\cdot} \mathrm{CH}_{3}\right) \cdot \mathrm{CH}\left(\mathrm{O} \cdot \mathrm{CH}_{3}\right) \cdot \mathrm{CH}^{\mathrm{C}} \cdot \mathrm{NH} \cdot \mathrm{C}_{6} \mathrm{H}_{5} \cdot
$$

Experiments are at present in progress, in which the constitution of glucoseanilide is being further investigated.

The results obtained on applying similar methods to tetramethyl glucosephenylhydrazone were not so conclusive. The product of the methylation failed to crystallise, and could not be distilled under diminished pressure on account of decomposition. On hydrolysis, however, in addition to aniline and methylaniline, a colourless dextrorotatory syrup was obtained, which did not affect Fehling's solution; it therefore contained no tetramethyl glucose. As the substance was easily resinified, we were unable to identify it definitely as pentamethyl glucose, although its reactions agreed with those which might be expected for such a compound. At all events, the absence of tetramethyl glucose in the hydrolysis products points to the conclusion that the hydrazone of tetramethyl glucose differs essentially in structure from the corresponding oxime and anilide.

The halogen derivatives of tetramethyl glucose, obtained by the action of phosphorus halides on the sugar, show considerable chemical similarity to those obtained from tetra-acetyl glucose. Both tetra- 
methyl chloroglucose and tetramethyl bromoglucose are uncrystallisable syrups, the latter being very unstable. Both compounds are decomposed by water, and react with methyl alcohol in presence of silver carbonate to give a mixture of the $\alpha$ - and $\beta$-tetramethyl methylglucosides, a result which indicates that the preparations are also mixtures of $a$ - and $\beta$-forms. Judging from the relative proportions of the two glucosides thus formed, and using this as an index of the composition of our preparation of tetramethyl chloroglucose, more than 70 per cent. of the $\beta$-form must have been present. The bromoderivative, like tetra-acetyl bromoglucose, could only be preserved for a few days without spontaneous decomposition. It was found that the substance could be applied synthetically in the formation of other alkylated glucosides. When dissolved, along with the molecular proportion of benzoin, in acetone and the solution heated with silver oxide, benzoin tetramethylglucoside, melting at $105-106^{\circ}$, was produced. This change, in which the alkylated sugar residue is introduced into the hydroxyl position, may be regarded as a modification of the silver oxide reaction.

We have also studied the action of a methyl-alcoholic solution of hydrogen chloride on tetramethyl glucose with the object of determining if the condensation of the alcohol and the sugar depends on the intermediate formation of an acetal compound. In previous cases (Trans., 1904, 85, 1063), this reaction has been conducted at $40^{\circ}$, using invariably $0 \cdot 25$ per cent. of hydrogen chloride, but in the present instance the effect of different concentrations of the acid at $20^{\circ}$ was ascertained polarimetrically. Using a methyl-alcoholic solution containing 5 per cent. of the sugar and 8 per cent. of hydrogen chloride, the specific rotation diminished very rapidly, but without fluctuation. The total optical change, which was complete in one hour, was $\alpha_{D}+79 \cdot 2^{\circ} \rightarrow+69 \cdot 1^{\circ}$. It will be seen that the initial rotation observed is lower than that found for tetramethyl glucose; this is doubtless due to the very rapid condensing action of the acid. The product consisted as usual of a mixture of the isomeric tetramethyl methylglucosides, and no indication of acetal formation was observed. A similar result was obtained by the substitution of 0.25 per cent. acid. In this case, the condensation was very slow at $20^{\circ}$, but the specific rotation of the solution, which was initially $+84 \cdot 8^{\circ}$, decreased steadily and ultimately became constant at $+70 \cdot 1^{\circ}$. The use of 0.1 per cent. acid naturally occasioned very slow reaction, but in this case the change of specific rotation was not regular. During the first twenty-four hours, a fall of $9^{\circ}$ in $[a]_{D}$ was observed; this was followed by a slow increase, occupying seventeen hours, to nearly the initial value. Thereafter the rotation diminished very slowly indeed, and the constant value, $[a]_{\mathrm{D}}+66 \cdot 8^{\circ}$, was only reached after the lapse of 
seven months. These optical changes cannot be ascribed to mutarotation of the sugar, or to the interconversion of the alkylated glucosides (Trans., 1904, 85, $1068 ; 1905,87,905)$, but, nevertheless, on examining samples of the solution at intervals, nothing was isolated from the product except the alkylated glucosides, mixed, when the condensation was incomplete, with quantities of unaltered tetramethyl glucose. This reaction therefore gives no indication of the sugar reacting in the aldehydic form.

The ready solubility of alkylated sugars in organic solvents enabled us to apply the Grignard reaction to tetramethyl glucose. This reaction has already been successfully carried out on tetra-acetyl-d-gluconolactone by Paal and Hörnstein (Ber., 1906, 39, 1361), who obtained $a \beta \gamma \delta \epsilon \zeta$-hexahydroxy-a $\alpha$-diphenylhexane as the main product. In our experiments, however, using magnesium methyl iodide, we have only obtained negative results so far, the alkylated sugar being recovered unaltered.

It will thus be seen that with the exception of the doubtful case of tetramethyl glucosehydrazone, all the derivatives so far obtained from tetramethyl glucose belong to the $\gamma$-oxidic type.

\section{Experimental.}

\section{Preparation of Tetramethyl Glucoseoxime.}

Ten grams of the alkylated sugar were dissolved in methyl alcohol (200 c.c.) containing slightly more than one molecular proportion of hydroxylamine, and the solution was boiled for 90 minutes under a reflux condenser. The alcohol was then evaporated, the crystalline residue dissolved in dry ether, and the solution filtered. On evaporation of the solvent, a colourless syrup remained, which rapidly solidified to a mass of slender, prismatic needles; these were drained from adherent oil on a porous plate. The finely-powdered substance was afterwards extracted repeatedly with boiling light petroleum in order to remove traces of unaltered tetramethyl glucose, and then recrystallised from a mixture of equal parts of light petroleum and anhydrous ether. When microscopically examined, the crystals appeared homogeneous, and, moreover, the specific rotations of successive crops were practically constant, but, nevertheless, after repeated crystallisation the melting point was rather indefinite $\left(61-68^{\circ}\right)$. Analysis gave :

$$
\begin{gathered}
\mathrm{C}=47 \cdot 51 ; \mathrm{H}=8 \cdot 44 ; \mathrm{CH}_{8} \cdot \mathrm{O}=48 \cdot 6 ; \mathrm{N}=6.01 . \\
\mathrm{C}_{6} \mathrm{H}_{9} \mathrm{O}_{2} \mathrm{~N}\left(\mathrm{O} \cdot \mathrm{CH}_{3}\right)_{4} \quad \text { requires } \mathrm{C}=47 \cdot 81 ; \mathrm{H}=8.36 ; \mathrm{CH}_{3} \cdot \mathrm{O}=49 \cdot 4 ; \\
\mathrm{N}=5.58 \text { per cent. }
\end{gathered}
$$

Tetramethyl glucoseoxime is readily soluble in water and all organic solvents with the exception of light petroleum, and the aqueous 
solution has no action on Fehling's solution in the cold, but effects vigorous reduction on boiling. A 5 per cent. solution in methyl alcohol showed a specific rotation of $+25 \cdot 9^{\circ}$, which remained unaltered after twenty-four hours. A similar solution in water gave $[a]_{\mathrm{D}}^{20}+27 \cdot 8^{\circ}$, and here, also, no evidence of mutarotation was observed even after several days.

The hydrolysis of the oxime was effected by heating with excess of 8 per cent. aqueous hydrogen chloride at $100^{\circ}$. The hydrolysis, how ever, commenced even at the ordinary temperature, as, on standing, the value for $[a]_{D}$ was found to decrease from $+27 \cdot 8^{\circ}$ to $+15 \cdot 0^{\circ}$. On now heating to $100^{\circ}$, the dextrorotation rapidly increased, and after fifty minutes' treatment remained constant. The value then obtained, if calculated on the basis that tetramethyl glucose was the only active product of the hydrolysis, was $+83 \cdot 7^{\circ}$, a number which agrees very closely with the constant specific rotation of the alkylated sugar in water. The solution was neutralised with barium carbonate, evaporated to dryness, and the residue extracted first with ether and afterwards with a mixture of alcohol and ether. The former extract gave tetramethyl glucose (m.p. $84-85^{\circ}$ ), and the latter hydroxylamine hydrochloride, and these substances constituted the sole products of the hydrolysis.

\section{Alkylation of Tetramethyl Glucoseoxime.}

On adding silver oxide ( 5 mols.) to tetramethyl glucoseoxime ( $1 \mathrm{~mol}$.) dissolved in methyl iodide (10 mols.), a vigorous, spontaneous reaction ensued, which was completed by heating on a water-bath for three hours. The product was extracted with boiling ether, and, on evaporation of the solvent, a clear, yellow, neutral liquid was obtained. After a second alkylation in which the same proportions of alkylating mixture were used, the compound was fractionated under diminished pressure (b. p. $144-146^{\circ}$ under $10 \mathrm{~mm}$. pressure). Analysis gave :

$\mathrm{C}=49.98 ; \mathrm{H}=8.60 ; \mathrm{CH}_{3} \cdot \mathrm{O}=57 \cdot 13 ; \mathrm{N}=5.56$.

$\mathrm{C}_{11} \mathrm{H}_{23} \mathrm{O}_{6} \mathrm{~N}$ requires $\mathrm{C}=49 \cdot 81 ; \mathrm{H}=8.68 ; \mathrm{CH}_{3} \cdot \mathrm{O}=58.49 ; \mathrm{N}=5.28$ per cent.

The analyses not only indicate that only one methoxyl group had been introduced, but exclude the possibility of the presence of pentamethyl glucononitrile.

The alkylated oxime is a colourless, neutral, mobile liquid, soluble in all ordinary solvents, and possessing no action on Fehling's solution except on prolonged boiling. The optical activity of different preparations was almost constant, a five per cent. solution in methyl alcohol giving $[\alpha]_{D}^{20}+39 \cdot 8^{\circ}$ without mutarotation. 


\section{Hydrolysis of Tetramethyl Glucoseoxime Methyl Ether.}

The hydrolysis of the alkylated oxime presented considerable difficulty. A 4 per cent. solution of the compound was prepared in water containing 5 per cent. of hydrogen chloride, and heated in boiling water. As in the case of the parent oxime, the dextro specific rotation at first diminished from $38 \cdot 1^{\circ}$ to $29 \cdot 8^{\circ}$, and afterwards steadily increased, during three hours' treatment, to the value $+50^{\circ}$. During the reaction, appreciable quantities of hydrogen cyanide were evolved, and, judging by the increase in specific rotatory power, the hydrolysis proceeded only slowly at $100^{\circ}$. Accordingly, the liquid was maintained at the boiling point, the evolved hydrogen cyanide being removed in a current of air. After six hours' treatment, the evolution of the gas ceased; the solution was neutralised with barium carbonate and worked up as usual. A nearly quantitative yield of tetramethyl glucose, melting after recrystallisation at $84^{\circ}$ and showing the specific rotation, $\left[a_{D}^{20}\right]+87 \cdot 8^{\circ}$, was obtained as the product of the hydrolysis.

\section{Alkylation of Different Types of Oximes.}

The methylation of these oximes was carried out for the purposes explained in the introduction.

Alkylation of Enanthaldoxime.-This substance was selected for experiment as a type of compound containing one hydroxyl group directly linked to the nitrogen atom. The oxime was readily soluble in methyl iodide, and was alkylated as usual by the joint action of the alkyl halide and dry silver oxide. After two treatments, the product was fractionated under reduced pressure, and obtained as a colourless liquid boiling at $65-66^{\circ}$ under $15 \mathrm{~mm}$. pressure.

Analysis pointed to the fact that methylation had proceeded normally :

Found, $\mathrm{C}=66.86 ; \mathrm{H}=11.71 ; \mathrm{CH}_{3} \cdot \mathrm{O}=19.50$. $\mathrm{C}_{7} \mathrm{H}_{14} \mathrm{~N} \cdot \mathrm{O} \cdot \mathrm{CH}_{3}$ requires $\mathrm{C}=67 \cdot 13 ; \mathrm{H}=11 \cdot 88 ; \mathrm{CH}_{3} \cdot \mathrm{O}=21 \cdot 68$ per cent.

Alkylation of Salicylaldoxime.-In the case of salicylaldoxime, the reaction with silver oxide and methyl iodide was very vigorous. The product was a mobile liquid, which was distilled at $125-127^{\circ}$, under $16 \mathrm{~mm}$. pressure. As the compound burned with explosive violence, ordinary combustions could not be undertaken, but a Zeisel estimation gave $\mathrm{CH}_{3} \cdot \mathrm{O}=37 \cdot 11$, the calculated value, assuming that two methoxyl groups had entered the molecule, being 37.57 per cent. The constitution of the compound was also proved by the formation of salicylaldehyde methyl ether during hydrolysis. As the melting point of the latter compound shows considerable variation, the product of the 
hydrolysis was identified by conversion into o-dimethoxybenzoin (Trans., 1901, 79, 670), melting at $101 \cdot 5^{\circ}$. This result shows that both the phenolic and oximido-groups present in the oxime had undergone normal alkylation.

Alkylation of Benzoinoxime.-In this case, two successive alkylations were found to be necessary, as the oxime did not dissolve readily in the alkyl iodide, and consequently the addition of acetone was necessary in the first treatment with the methylating agents. The product was obtained as a colourless oil boiling at $182-184^{\circ}$ under $16 \mathrm{~mm}$. pressure. Analysis gave:

$$
\begin{aligned}
& \mathrm{C}=74 \cdot 94 ; \mathrm{H}=6 \cdot 85 ; \mathrm{N}=5 \cdot 66 . \\
& \mathrm{C}_{14} \mathrm{H}_{11} \mathrm{~N}\left(\mathrm{O} \cdot \mathrm{CH}_{3}\right)_{2} \text { requires } \mathrm{C}=75 \cdot 29 ; \mathrm{H}=6.66 ; \mathrm{N}=5 \cdot 4.7 \text { per cent. }
\end{aligned}
$$

As the compound resinified with hydrogen iodide, the results of the methoxyl determinations were invariably low (found, $\mathrm{CH}_{3} \cdot \mathrm{O}=18 \cdot 22$, calculated for two methoxyl groups, $\mathrm{CH}_{3} \cdot \mathrm{O}=24 \cdot 31$ per cent.). The presence of a methoxyl group in the benzoin side-chain was, however, confirmed by hydrolysis. This was effected by boiling in aqueous alcoholic solution containing 8 per cent. of hydrogen chloride. After two hours' treatment, the product was precipitated with water and extracted with ether. The ethereal extract, after treatment with sodium carbonate, yielded on evaporation a crystalline product which, after recrystallisation from light petroleum, melted at $49-51^{\circ}$, and was therefore identified as benzoin methyl ether.

\section{Tetramethyl Glucoseanilide.}

On boiling an alcoholic solution of equimolecular proportions of the sugar andianiline for several hours, partial condensation took place with the formation of tetramethyl glucoseanilide. The yield of the latter was, however, materially increased by using a considerable excess of the base. Equal weights of tetramethyl glucose and aniline were dissolved in the minimum quantity of absolute alcohol, and the solution was boiled for four hours. As the crude anilide darkened rapidly when heated to $100^{\circ}$, the removal of the solvent alcohol and excess of aniline was effected by heating to $60^{\circ}$ under reduced pressure. The semi-crystalline residue was drained on a porous tile, washed with cold water to remove traces of the sugar, and recrystallised twice from anhydrous ether. Analysis gave:

$$
\begin{aligned}
& \mathrm{C}=61 \cdot 50 ; \mathrm{H}=8 \cdot 18 ; \mathrm{CH}_{3} \cdot \mathrm{O}=40 \cdot 49 . \\
& \mathrm{C}_{16} \mathrm{H}_{25} \mathrm{O}_{5} \mathrm{~N} \text { requires } \mathrm{C}=61 \cdot 74 ; \mathrm{H}=8.04 ; \mathrm{CH}_{3} \cdot \mathrm{O}=39 \cdot 87 \text { per cent. }
\end{aligned}
$$

The anilide crystallises from ether in long needles, melting sharply at $135^{\circ}$, and is apparently homogeneous. It is readily soluble in organic solvents, but is practically insoluble in water. When boiled 
for a considerable time with water, the substance is partly hydrolysed. The specific rotation of a 3 per cent. solution in acetone was $[a]_{\mathbf{D}}^{20}+229 \cdot 5^{\circ}$, and no mutarotation was detected even after adding a trace of alcoholic ammonia. The compound was hydrolysed by mixing an acetone solution with an equal volume of 10 per cent. hydrogen chloride and heating to $50^{\circ}$. The dextrorotation diminished steadily without fluctuation, and, on working up the products, tetramethyl glucose and aniline were isolated.

\section{Attempted Alkylation of T'etramethyl Glucosideanilide.}

The methylation of the compound was attempted in order to determine whether the anilide is a condensation derivative of the sugar in its aldehydic or $\gamma$-oxidic form. A solution of the compound ( $1 \mathrm{~mol}$.) in methyl iodide (10 mols.) was heated on a water-bath with silver oxide (5 mols.). There was no apparent reaction, and on working up the product after several hours' treatment the original weight of anilide was recovered unaltered in melting point and specific rotation. A second alkylation was tried, in which heating with a large excess of the alkylating mixture was continued for three days, but with a similar result. Additional evidence that no alkylation had occurred was furnished by the fact that only 8 per cent. of the silver oxide was converted into iodide. As in no previous case has any hydroxycompound resisted this treatment, we conclude that the anilide is a $\gamma$-oxidic form.

\section{Alkylation of Tetramethyl Glucosephenylhydrazone.}

The hydrazone was prepared as already described (Trans., 1903, 83, 1033), and alkylated in the usual manner. The crude product, which was a bright red syrup insoluble in water or light petroleum, but readily soluble in organic solvents generally, could not be obtained in a crystalline state. The syrup gave in methyl-alcoholic solution $[a]_{D}^{20}+24 \cdot 7^{\circ}$, a value which does not differ notably from the rotatory power of the parent hydrazone $\left([a]_{\mathrm{D}}^{20}+16 \cdot 6^{\circ}\right)$. When heated under reduced pressure, the compound decomposed; even on standing at the ordinary temperature, the red colour became much darker, and accordingly no analyses were attempted. The hydrolysis of the product of alkylation was, however, undertaken in the hope of gaining information as to the probable constitution of the compound. When boiled for ten hours with aqueous methyl alcohol containing 4 per cent. of hydrogen chloride, no appreciable change occurred, and consequently the acid was replaced by very dilute aqueous sodium hydroxide, which has no appreciable action on tetramethyl glucose. On now heating on a water-bath, a quantity of gas was disengaged, which was absorbed in 
hydrochloric acid, the solution giving the test for a primary amine. The mixture was then distilled with steam, and the volatile oils were converted into the hydrochlorides and treated with nitrous acid. The oily precipitate thus formed was extracted with ether, the solvent evaporated, and the residual oil mixed with concentrated sulphuric acid. The formation of a dark blue colour showed the joint presence of phenol and nitrosoamine, proving that both aniline and methylaniline must have been produced in the hydrolysis. The aqueous product of the hydrolysis was neutralised and worked up as usual. In this way, a colourless, uncrystallisable, neutral syrup was obtained, which had no action on Fehling's solution even after heating with acids. In alcoholic solution, the substance was strongly dextrorotatory. The compound, which became resinous on standing, could not be obtained in a pure form, and consequently was not further examined, but its behaviour agrees approximately with the probable reactions of pentamethyl glucose in its aldehydic form. The combined results of the hydrolysis therefore point to the conclusion that alkylation of the hydrazone leads to the introduction of two methyl groups, one in the $\gamma$-position in the sugar-chain, and the other in the phenylhydrazine residue. This result differs sharply from those obtained in the case of the oxime or anilide, where the sugar residue in the molecule was not affected by further alkylation.

\section{Halogen Derivatives of Tetramethyl Glucose.}

T'etramethyl chloroglucose was prepared by heating a 10 per cent. solution of the sugar in benzene with the molecular proportion of phosphorus pentachloride. The reaction was carried out on a water-bath, and was continued for thirty minutes. The benzene was then removed under diminished pressure, the residue dissolved in ether, and shaken repeatedly with water. The ethereal extract was dried over anhydrous sodium sulphate, and shaken successively with barium carbonate and silver carbonate. On evaporation of the solvent, a colourless oil remained, soluble in organic solvents, but insoluble in cold water. When warmed with water, the oil passed readily into solution with the formation of tetramethyl glucose and hydrogen chloride. The substance, which was free from phosphorus compounds, was completely decomposed on heating in a vacuum to $140^{\circ}$. Without further purification, the product gave :

$\mathrm{Cl}=12 \cdot 71$.

$$
\mathrm{C}_{10} \mathrm{H}_{19} \mathrm{O}_{5} \mathrm{Cl} \text { requires } \mathrm{Cl}=13.95 \text { per cent. }
$$

The specific rotation in methyl a!cohol, which can only, of course, be regarded as appreximate, was $[a]_{0}^{201}+154^{\circ}$. 
On shaking the solution at $20^{\circ}$ with silver carbonate, the rotatory power gradually diminished, and in forty-eight hours attained the constant value $[\alpha]_{0}^{20}+40^{\circ}$. The product of the action was a neutral syrup, which was easily recognisable as a mixture of $\alpha$-and $\beta$-tetramethyl methylglucosides, as on hydrolysis with hydrogen chloride the specific rotation increased from $+40^{\circ}$ to $+94^{\circ}$ and then diminished to $+85^{\circ}$. The sole product of the hydrolysis was tetramethyl glucose.

It was afterwards found that tetramethyl $a$-methylglucoside might be substituted for tetramethyl glucose in the above preparation, thereby facilitating the process considerably.

Tetramethyl Bromoglucose.-This compound was prepared by the action of phosphorus pentabromide on the sugar, the details of the process being similar to those described above for the chloroderivative, except that in all the operations the temperature bad to be restricted below $80^{\circ}$, as above this the product was decomposed. The substance resembled the chloro-derivative, but was much more unstable; even when preserved in a vacuum and in the dark, complete decomposition took place in a few days. The specific rotation of a freshly prepared specimen in acetone solution was $[a]_{\mathrm{D}}^{20}+45 \cdot 9^{\circ}$. When heated with water at $100^{\circ}$, the compound was completely decomposed with the formation of tetramethyl glucose and hydrogen bromide. Using this reaction as a means of estimating the bromine, analysis gave:

$$
\mathrm{Br}=26 \cdot 61 \text {. }
$$

$$
\mathrm{C}_{10} \mathrm{H}_{19} \mathrm{O}_{5} \mathrm{Br} \text { requires } \mathrm{Br}=26 \cdot 75 \text { per cent. }
$$

When shaken in methyl-alcoholic solution with silver carbonate, a mixture of the isomeric tetramethyl methylglucosides was obtained, the $\beta$-form being produced in large excess. The same result was more rapidly arrived at by heating the bromo-compound with methyl alcohol and silver oxide.

\section{Application of the Grignard Reaction to Tetramethyl Glucose.}

On adding a solution of the sugar in dry ether to a similar solution of magnesium methyl iodide, a fairly vigorous reaction ensued, which was continued on a water-bath for thirty minutes. The product was hydrolysed with dilute sulphuric aoid and extracted with ether. The ethereal extract after drying over sodium sulphate gave a crystalline residue on evaporation. This was recrystallised several times from light petroleum, and the specific rotation of each crop determined in methyl-alcoholic solution. As in each case the various products melted at $84-85^{\circ}$ and gave the constant specific rotation $[a]_{\mathcal{D}}^{20}+84^{\circ}$, 
$\begin{array}{llll}\text { STUDIES OF DYNAMIC ISOMERISM. PART VI. } & 107\end{array}$

it was evident that they consisted of the alkylated sugar, over 80 per cent. of which was recovered unaltered.

The authors desire to acknowledge their indebtedness to the Carnegie Trust for a grant in aid of this investigation, and also to Professor Purdie for much valuable advice.

Chemical Research Laboratory,

United College of St. Salvator and St. Leonard,

UNivensity of ST. ANDREWS. 